\title{
Artificial intelligence and internet of things for sustainable development - emerging techno- logical and social opportunities and threats
}

\author{
Marta R. Jabłońska ${ }^{1, *}$, and Radosław Zajdel ${ }^{1}$ \\ ${ }^{1}$ University of Łódź, Department of Computer Science In Economics, Institute of Applied Economics \\ and Informatics, Faculty of Economics and Sociology, 37 Rewolucji 1905 r. St., 90-214 Łódź, Poland
}

\begin{abstract}
Artificial Intelligence (AI) and Internet of Things (IoT) are those which will bring a bright future for sustainable development by reducing an unsustainability that disturbs societies, environment, and natural resources. The rapid and multidisciplinary AI and IoT evolution, the relative novelty of the concept itself and little literature concerning their role in sustainable development goals achieving, present an area for further research. Our aim is to research AI and IoT potential and risk for reaching sustainable development, focusing on a job market. We conducted a bibliometric analysis concerning these technologies impact on sustainable development goals achieving, especially technical factors and labor market impact. Results proved that AI and IoT massive deployment brings real threats, still, opportunities and possible benefits that are sought overbalance potential risks.
\end{abstract}

\section{Introduction}

The sustainable development is a widely accepted paradigm that social, economic, and environmental growth should meet the needs of the present, without threatening the ability of future generations to meet their own needs [1]. Around the globe many countries still stress with unsustainable economies, policies, infrastructure and industrialization. This imbalance disturbs societies, environment, and natural resources. With the surging complexity of achieving sustainable development's goals, new technologies, especially those based on AI and the IoT, are required as they offer realistic opportunities [2, 3, 4]. AI already has begun to gain prominence in various applications in exploring and unraveling the complex logic patterns, forecasting, optimizing, automation, planning, managing and many more. Machine learning and deep learning techniques are used for decision making, anomaly detection, early-warning, classification, structured prediction, speech and image recognition, dimensionality reduction, regression, and clustering [5]. AI is perceived as a crucial factor of IoT paradigm employment, especially when it comes to forecasting and decision support $[6,7]$. The IoT is seen as a megatrend in next-generation technologies with a huge possible impact on economy, society and environment. By using existing internet infrastructure, it realizes human-to-machine, human-to-human, and machine-to-machine

\footnotetext{
*Corresponding author: marta.jablonska@uni.lodz.pl
} 
communication that integrates various devices and its extend benefits $[8,9]$. The IoT is an abstraction of limitless objects with unique identities, equipped with some level of Internetaddressable AI and connected to create an ultimate cyber-physical pervasive framework. Connected virtual and physical objects collect data automatically or manually, monitor and transmit data to facilitate a new level of automation [10-13]. Such network is comprised of hardware (sensors, sensor actuators, embedded communications board, RFID), midware (cloud computing, data storage, data centers), and visualization systems (human-computer interaction interfaces, data interpretation, and event resolving) $[6,14,15]$.

Although researchers agree on benefits that AI and IoT may bring to sustainable development goals achieving, there are still concerns about how to apply these techniques to bring new opportunities and benefits to the economy, environment, people and society, also considerable technical, legal and socio-economic challenges remain to be addressed [3, $10,16]$. In this paper, we use an exploratory approach to discuss how we can tackle AI and IoT in the service of sustainable development from a not only technical view but also from labor market impact perspectives. We seek to bridge some of the theoretical gaps about how AI and IoT implementation may serve but also influence sustainable development goals achieving.

\section{Materials and methods}

To review available literature, we selected two databases into analysis: Web of Science and Scopus. Both are abstract and citation databases providing a comprehensive citation search by allowing access to multiple databases which reference cross-disciplinary research. Most bibliometric analyses use one: Thomson Reuters' Web of Science or Elsevier's Scopus. As their coverage differs substantially, the results of bibliometric analyses may vary depending on the database used [17]. In order to prevent such biases, we used both databases in our study.

A set of queries (including manuscript's title, topic, abstract, author keywords, engineering controlled terms and engineering main heading) was performed on each database to select works describing AI and IoT in context of sustainable development. As both raise their popularity and practical applications recently, we set our timespan for 5 years. This assumption was confirmed by poor results from Web of Science and Scopus concerning older manuscripts. Duplicated records were removed and we checked each record manually to provide full coverage with the topic due to the fact that a vast part of results concerned AI or IoT separately, without sustainable development context (Table 1.). Due to author keywords, engineering controlled terms and engineering main heading, each manuscript was assigned to a specific area from predefined list that we previously designed on the basis on searching results.

Table 1. Number of analyzed manuscripts.

\begin{tabular}{|l|l|c|c|c|}
\hline \multirow{2}{*}{ Database } & \multirow{2}{*}{ Area } & Results & \multicolumn{2}{c|}{ After verification } \\
\cline { 3 - 5 } & & $\mathbf{N}$ & $\mathbf{N}$ & $\mathbf{\%}$ \\
\hline \multirow{2}{*}{ Web of Science Core Collection } & AI & 70 & 54 & $77.14 \%$ \\
\cline { 2 - 5 } & IoT & 174 & 121 & $69.54 \%$ \\
\hline \multirow{2}{*}{ Scopus } & AI & 735 & 281 & $38.23 \%$ \\
\cline { 2 - 5 } & IoT & 456 & 183 & $40.13 \%$ \\
\hline Total & & $\mathbf{1 4 3 5}$ & $\mathbf{6 3 9}$ & $\mathbf{4 4 . 5 3 \%}$ \\
\hline
\end{tabular}

Among verified manuscripts, 59 were provided in open access. They were used for further detailed analysis. Number of works concerning year of publication equals to $2013-$ 
62, 2014 - 56, 2015 - 84, 2016 - 143, 2017 - 2020, and June 2018 - 92. Gathered material comprised of 287 articles, 332 proceeding papers, 13 book chapters, and 7 books.

\section{Results}

\subsection{Sustainable development's areas for Al and loT deployment}

Sustainable development may be achieved in many vital areas i.e.: economics, finance, management, marketing, research and development, transportation, energy, environment, ecology, healthcare $[2,18]$.

Results including number of works assigned to the most popular list of topics and the most commonly used engineering controlled terms and keywords compared to full texts analysis, map out sustainable development's areas of AI and IoT deployment: power sector $[5,11,19,20]$, smart city [7, 9, 11, 21-26], architectural design and smart buildings [2729], transportation, tracking systems, traffic congestion and smart roads [7, 9, 11, 13, 25], company operations, business development [8, 30-32], manufacturing and industrial control $[9,10,16,33-36]$, product design and lifecycle [34, 37], threat identification systems, earlywarning systems, emergency services, tracking and surveillance [7, 9], agriculture [38, 39], natural resources management, especially water resources $[4,6,7,40]$, waste management [9-11], healthcare services and systems [7, 9, 10, 41], smart society [7, 13, 42], and policymaking process and e-governance $[11,35,43]$. Although AI and IoT may be implemented in a broad scope of areas, applied solutions are not so differential. AI techniques are most commonly used in decision support systems, while IoT is remolded into new paradigms: Industrial IoT (IIoT), Environmental IoT (EIoT), ZeroIoT, Green IoT, and Social IoT. IIoT (or Industry 4.0) is related to smart factory and employs cyber-physical systems to support decentralized decision-making and monitor the physical production processes including engineering, material usage, supply chains, and product lifecycle management $[16,33,35]$. The EIoT's aim is to bolster urban environmental science in planning, construction, and management of sustainable cities [26]. ZeroIoT (also ZeroSpace Interconnection of Things) is one of possible future development directions for the IoT, able to realize the processes in the time, space, error and insecurity all approaching zero [44]. IoT characterized by energy efficiency, focused on reducing the energy consumption, greenhouse effect or even greenhouse footprint is known as Green IoT [15]. The future sensor-cloud may also evolve into social-sensor-cloud (SSC) using in symbiosis WSNs, social media and cloud computing $[15,45]$.

\subsection{Technical determinants}

AI and IoT are set to become one of the key technological features of sustainable development goals achieving if we are able to realize their full potential [7]. As smart, learning, autonomous technologies, they offer a new standard of processes realization, still not without flaws at the same time (Table 2.).

Table 2. AI and IoT implementation's pros and cons.

\begin{tabular}{|l|l|l|}
\hline & \multicolumn{1}{|c|}{ Benefits } & \multicolumn{1}{|c|}{ Weaknesses } \\
\hline AI & Superiority in time series processing [5]; & Predictions without knowing the \\
& Capability to deal with noise data [5]; & internal relationship between variables \\
& $\begin{array}{l}\text { Higher prediction accuracy in terms of } \\
\text { MAE, MSE, MAPE, and RMSE errors }\end{array}$ & $\begin{array}{l}\text { A } 47] ; \\
\text { A spurious regression problem occurs } \\
\text { in a wide range of time series analysis }\end{array}$ \\
\hline
\end{tabular}




\begin{tabular}{|c|c|c|}
\hline & Benefits & Weaknesses \\
\hline & $\begin{array}{l}\text { Shortening analysis time allows to identify } \\
\text { problems earlier, allowing decision makers } \\
\text { to be proactive not reactive [4]; } \\
\text { Improving diagnostic procedures by } \\
\text { recognizing subtle patterns }[10]\end{array}$ & $\begin{array}{l}\text { in econometrics owing to its } \\
\text { nonstationarity [5]; } \\
\text { Learning algorithms overfitting, } \\
\text { subject to local convergence and slow } \\
\text { learning [48] }\end{array}$ \\
\hline IoT & $\begin{array}{l}\text { Effective in terms of energy consumption, } \\
\text { CPU and memory usage [49]; } \\
\text { Improving automation, asset utilization, } \\
\text { employees productivity, supply chain } \\
\text { management, customer experience, } \\
\text { resource efficiency [10,33]; } \\
\text { Reducing time to market [10]; } \\
\text { Creating full transparency along the value } \\
\text { chain for informed environmental } \\
\text { management [50]; } \\
\text { Strengthening the sustainable energy role } \\
\text { in manufacturing [33] }\end{array}$ & $\begin{array}{l}\text { Lack of fully defined standards for IoT } \\
\text { architectures }[9,22] \text {; } \\
\text { Little comparative study has offered } \\
\text { any evidence of low-cost of IoT-based } \\
\text { services [9]; } \\
\text { Power requirements in finding an } \\
\text { appropriate device discovery protocol } \\
\text { are still difficult to find [9] }\end{array}$ \\
\hline
\end{tabular}

$\mathrm{AI}$ and IoT offer realistic opportunities for sustainable development. Present systems have to deal with online misinformation, completing missing information, ultimately underutilized data stored in various platforms, lack of frameworks that facilitate data sharing, heterogeneity of data containing much irrelevant information. AI and IoT-based solutions are able to reduce those flaws and improve systems operations, as well as decision-making processes $[3,4]$. Thus, AI and IoT may bring new opportunities for decision makers in business, but also in the public sector by setting up policies or upgrading a country's industrial level and global competitive priority and sustainability [30].

As these emerging technologies will link various aspect of everyday life and business operations to the Internet by using massive amount of devices and sensors, various threats to the security and privacy of consumer data will occur. Comparing to previous technologies, their impact will be more profound, irreversible, and fast [16]. Diverse threats and challenges are mentioned in literature: stringent requirements of sophisticated systems' architectures, exposing IoT devices to vulnerabilities, lack of standardization, difficulties in seamless transition from old technologies, services availability and sca lability, developing new business models, assuring quality of service, and ethical and privacy concerns $[9,10$, 51]. Security and privacy of data may be threaten as sending data without any encryption by sensors due to their limited computational power, outsourced storage and computation [10]. That is why AI and IoT-based solutions may be vulnerable to cyber attacks, including: installing malware, physical, time delay, data tampering, denial of service (DoS), false data injection, side channel, covert-channel, eavesdropping, replay, spoofing, zero day-attacks, and those against AI analytics [52,53]. Attacks may be performed individual criminals or organized networks of criminal entities, terrorist groups, rival organizations, hacker hobbyists, patriotic hackers often driven by a political ideal, or even insiders possessing access to the organization's assets (current and former employees, business partners, service providers, vendors, guests) [52]. Important threat raised also on social background as employees using AI and IoT applications, may argue that these technologies cause a conflict of interest with them, feel unsecure about future employment and refuse to use them [51]. AI and IoT potential influence on labor market has raised so many threats and expectations that a separate section was devoted to it. 


\subsection{Labor market influence}

The information technology revolution has already had dramatic impact (both in terms of quantity and the nature of jobs) on the labor market, and emerging technologies will go even further [53]. Some research predict a necessity to create 600 million new jobs in the next 15 years, mainly in Asia and Sub-Saharan Africa, as well as replacing 137 million people jobs in Southeast Asia within 20 years, mainly due to the AI and IoT [54]. Job losses may occur due to the automation of large segments of operations in many industries and new opportunities may appear for high-skilled employees, especially in developed countries [16]. Table 3. presents possible opportunities and threats for employees raised from AI and IoT deployment.

Table 3. New technologies impact on labor market.

\begin{tabular}{|c|c|}
\hline $\begin{array}{r}\text { New o } \\
\text { imp }\end{array}$ & $\begin{array}{c}\text { Job losses arguments from implementation of } \\
\text { AI and IoT }\end{array}$ \\
\hline $\begin{array}{l}\text { New job opportunities requiring high } \\
\text { skills }[16,54] \text {; } \\
\text { Augmentation of human capacity and } \\
\text { the effectiveness of human potential } \\
{[10] \text {; }} \\
\text { Freeding up capacities of the } \\
\text { employees to engage in non-routine } \\
\text { decisions and tasks [10, 55]; } \\
\text { Simplification of the work tasks at } \\
\text { the level of skilled work [55]; } \\
\text { Developing expert systems as a tool } \\
\text { for qualified skilled workers [55]; } \\
\text { Employees could focus mainly on } \\
\text { social interactions, collaboration, } \\
\text { continuous improvement, and } \\
\text { innovation [53]; } \\
\text { High-skill jobs will become more } \\
\text { intrinsically motivating, diverse, } \\
\text { enabling more skills, and } \\
\text { decentralization [53]. }\end{array}$ & $\begin{array}{l}\text { Jobs may become redundant or reduced through } \\
\text { automation and the digitization [16]; } \\
\text { Reduced demand for mid-skill workers [53]; } \\
\text { Providing quicker, more accurate and fact-based } \\
\text { performances comparing to human work [10]; } \\
\text { Limitation of the autonomy of accomplished } \\
\text { skilled workforce [55]; } \\
\text { Reduced motivation for middle-skill jobs due to } \\
\text { fewer tasks and skills, more centralization and } \\
\text { monitoring [53]; } \\
\text { The qualification requirements of new jobs will be } \\
\text { more strict [16]; } \\
\text { Elimination of a possible human error source [55]; } \\
\text { Lower qualified personnel can be quickly } \\
\text { deployed at lesser wages [55]; } \\
\text { Reduced extended on-the-job training for lower } \\
\text { qualified workforce [55]; } \\
\text { Vast numbers of job seekers will require financial } \\
\text { support to catch up with new jobs [56]; } \\
\text { Decrease of demand for manufacturing work in } \\
\text { high-income countries [54]; } \\
\text { The skill sets for today's jobs will be totally } \\
\text { changed [54]. }\end{array}$ \\
\hline
\end{tabular}

$\mathrm{AI}$ and IoT are no longer confined to routine jobs, delivery people that can be easily automated but are spreading to non-routine jobs. The list of occupations that may become redundant or obsolete includes: manufacturers, farmers, call center agents, train and cab drivers, cooks, waiters, cleaners, cashiers, receptionists, medical doctors, nurses, lawyers, accountants, architects, financiers, analysts, insurers, software engineers, programmers, recruiters, musicians, writers, actors, salesmen, teachers and professors $[10,51,56,57]$.

Emerging technologies may be also used for job organization. First systems for enterprises to recruit, select, employ, foster, and develop long-term competence of employees were already described in current literature [35, 58].

Despite vast part of human mental and physical labor will sooner or later be replaced by $\mathrm{AI}$ and IoT, complex cognitive skills, including creativity and social-emotional intelligence, will be less replaceable, providing expanding employment opportunities for occupations for some time. Although some researchers are worried that the role of the human actors will be 
taking a back seat, one billion people will be unemployed worldwide, or that we experience a dramatic labor market contraction and then its unpredictable transformation, we may assume that new jobs might be invented and many of them will integrate human and machine 'intelligence' in a symbiotic way $[55,56,59]$.

\section{Discussion}

Our findings seem to prove the important role that AI and IoT may play in sustainable development goals achieving. Still, setting up highly efficient, reliable and accurate systems could remain a great future challenge [7]. Such solutions require adequate business models to regulate revenues distribution to cover involved subjects costs, security mechanism to protect data against unauthorized access and malicious actors, anonymizing algorithms for strong analyses, standards for acquiring interoperability, algorithms and storage solutions for big data operations, interaction models for increasing usability, and efforts to make users involved AI and IoT systems deployment processes [13]. We extracted a set of key requirements to enable more reliable systems: security (regulations, standards and guidelines deployment, end-to-end security mechanisms, intrusion detection systems, post incident management, data encryption, configurable authorization control, users security skills training), data (data fusion, enforced formal data sharing frameworks, cloudcomputing, nonrigid SQL databases, automated collection and analyses) flexibility (open APIs, device and sensors manageability, constant development through networking and device agnosticism) [3, 7, 22, 52].

As another recommendation to improve the AI and IoT-based platforms' protocols, algorithms, and hardware design and to decrease the risk of non-professional project deployment, we suggest performing pilot projects as they are able to match the apt risk mitigation and application development strategies [51]. As, due to the fusion of wireless IoT and AI, future systems will be becoming context-aware, intelligent and able take into account the users' preferences, a collaboration between all involved subjects (system developers, data scientists, users, policy-makers, etc.) should be established [11]. Every designed solution should stand on six pillars: social, management, economic, legal, technology, and sustainability to preserve the security, technical, ethical and privacy concerns $[10,60]$. Introducing AI and IoT to our business, economic and social reality, we have to focus on the alignment between technical development in one hand and the new practices required to deal with social challenges, including labor market impact on the other [16].

\section{Conclusions}

Emerging technologies such as AI and IoT are perceived in current research as possessing a significant impact on sustainable development goals achieving. In this paper, we conducted a bibliometric study focused on technical determinants of their deployment as well as potential impact on future labor market. AI and IoT are mature enough to become widely spread, but their impact is still a subject of a debate if opportunities overcome potential threats or not. Thus such studies should be carried out to better understand the nature of these technologies.

As our study may be a valuable contribution to all business, government, policy-making and research subjects involved in AI and IoT-based systems deployment in order to provide more sustainability, we are aware that is possesses certain limitation. Despite we used two immense databases in our study, we can't provide a full coverage of all conducted studies. Still, we strongly believe that a coverage that Web of Science and Scopus provide 
(including the most prestigious journals with impact factors as well as current books and conference proceedings), will ensure a comprehensive description of current state of art.

\section{References}

1. J. Sujata, S. Saksham, G. Tanvi, Shreya, Procedia Computer Science 93, 902-909 (2016)

2. K-Y Shen, G-H. Tzeng, Sustainability 10, 1600 (2018)

3. L. Fernandez-Luque, M. Imran, Int. J. Med. Inform. 114, 136-142 (2018)

4. D. Ghernaout, M. Aichouni, A. Alghamdi, International Journal of Advanced and Applied Sciences 5(3), 89-97 (2018)

5. J. Huang, Y. Tang, S. Chen, Math. Probl. Eng. 5194810 (2018)

6. D. Koo, K. Piratla, J. Matthews, Procedia Engineering 118, 489-497 (2015)

7. F. Alam, R. Mehmood, I. Katib, N.N. Albogami, A. Albeshri, IEEE Access 5, 95339554 (2017)

8. Y. Jin, S. Ji, Eurasip. J. Wirel. Comm. 2018:96 (2018)

9. $\quad$ S.M.R. Islam, D. Kwak, M.H. Kabir, M. Hossain, K.S. Kwak, IEEE Access 3, 678708 (2015)

10. S. Latif, J. Qadir, S. Farooq, M.A. Imran, Future Internet 9, 93 (2017)

11. P. Lynggaard, K.E. Skouby, Sensors 16, 1840 (2016)

12. L. Yao, Q.Z. Sheng, S. Dustdar, IEEE Internet Comput. 19(4) 60-67 (2015)

13. P. Davidsson, B. Hajinasab, J. Holmgren, Å. Jevinger, J.A. Persson, Sustainability 8, 1248 (2016)

14. J.Gubbi, R. Buyya, S. Marusic, M. Palaniswani, Future Gener. Comp. Sy. 29, 16451660 (2013)

15. C. Zhu, V.C.M. Leung, L. Shu, E.C.H. Ngai, IEEE Access 3, 2151-2162 (2015)

16. R. Morrar, H. Arman, S. Mousa, Technology Innovation Management Review 7(11), $12-20$

17. P.Mongeon, A. Paul-Hus, Scientometrics 106, 213 (2016)

18. B. Hopwood, M. Mellor, G. O’Brien, Sustain. Dev. 13, 38-52 (2005)

19. S.B. Ghugare, S. Tiwary, S.S. Tambe, Int. J. Syst. Assur. Eng. Manag. 8(Suppl 4), 2083 (2017)

20. M. Bigoloni, S. Filipponi, Monet: Energy Procedia 111, 846-855 (2017)

21. K. Zhang, L. Lin, X. Huang, Y. Liu, Y. Zhang, IOP Conf. Ser.: Mater. Sci. Eng. 242, 012120 (2017)

22. M. Nitti, V. Pilloni, D. Giusto, V. Popescu, Mob. Inf. Syst. 2017, 9201640 (2017)

23. A. Hosein G. Hoseini, N.D. Dahlan, U. Berardi, A.G. Hoseini, N. Makaremi, Renew. Sust. Energ. Rev. 24, 593-607 (2013)

24. J. Jin, J. Gubbi, S. Marusic, M. Palaniswami, IEEE Internet Things J. 1(2), 112-121 (2014)

25. J. Lanza, L. Sánchez, V. Gutiérrez, J.A. Galache, J.R. Santana, P. Sotres, L. Muñoz, Energies 9, 719 (2016)

26. J. Zhao, X. Zheng, R. Dong, G. Shao, Int. J. Sust. Dev. World 20(3), 195-198 (2013) 
27. D. Casado-Mansilla, I. Moschos, O. Kamara-Esteban, A.C. Tsolakis, C.E. Borges, S. Krinidis, A. Irizar-Arrieta, K. Konstantinos, A. Pijoan, D. Tzovaras, D. López-DeIpiña, IEEE Access 6, 31444-31456.

28. A. Serrano-Jiménez, Á. Barrios-Padura, M. Molina-Huelva, Sustainable Cities and Society 39, 144-154 (2018)

29. L. Guardigli, M.A. Bragadin, F. Della Fornace, C. Mazzoli, D. Prati, Buildings 166, 48-59 (2018)

30. T.-M. Chang, M.-F. Hsu, S.-J. Lin, Inform Science. 424, 273-286 (2018)

31. I.-Y. Lu, T. Kuo, T.-S. Lin, G.-H. Tzeng, S.-L. Huang, Sustainability 8(7), 646 (2016)

32. M. Zdravković, O. Noran, H. Panetto, M. Trajanović, Comput. Sci. Inform. Syst. 12(3), 1009-1031 (2015)

33. G. Beier, S. Niehoff, B. Xue, Appl. Sci. 8, 219 (2018)

34. A.K. Kulatunga, N. Karunatilake, N. Weerasinghe, R.K. Ihalawatta, Procedia CIRP 26, 87-92 (2015)

35. K.C. Lin, J.Z. Shyu, K. Ding, Sustainability 9, 786 (2017)

36. S. Wang, J. Wan, D. Li, Ch. Zhang, Int. J. Distrib. Sens. Netw. 2016, 1-10 (2016)

37. S. Adhitya, B. Davis, R. Frankjaer, P. Flanagan, Z. Mahony, TEI '16 Proceedings, 627-634 (2016)

38. Y.-P. Lin, J.R. Petway, J. Anthony, H. Mukhtar, S.-W. Liao, C.-F. Chou, Y.-F. Ho, Environments 4(3), 50 (2017)

39. P. Riegler-Nurscher, J. Prankl, T. Bauer, P. Strauss, H. Prankl, Biosyst. Eng. 169, 188-198 (2018)

40. T.-S. Uen, F.-J. Chang, Y. Zhou, W.-P. Tsai, Sci. Total. Environ. 633, 341-351 (2018)

41. B. Xu, L.D. Xu, H. Cai, C. Xie, J. Hu, F. Bu, IEEE Trans. Ind. Informat. 10(2), 1578$1586(2014)$

42. C. Li, H. Zhou, Sustainability 10(2), 468 (2018)

43. G.Á. Horváth, P. Harazin, J. Clean. Prod. 114, 214-223 (2016)

44. J. Zhao, X. Liu, R. Dong, G. Shao, Int. J. Sust. Dev. World 23(4), 293-297 (2016)

45. Y. Jiang, J.C. Jiang, IEEE Trans. Parallel Distrib. Syst. 25(10), 2743-2759 (2014)

46. L. Liu, J. Huang, S.W. Yu, Chinese Journal of Population Resources and Environment 14(1), 16-29 (2016)

47. M.E. Günay, Energ. Policy 90, 92-101 (2016)

48. N. Zaini, M.A. Malek, M. Yusoff, N.H. Mardi, S. Norhisham, IOP Conf. Series: Earth and Environmental Science 140, 012035 (2018)

49. G. Aloi, G. Caliciuri, G. Fortino, R. Gravina, P. Pace, W. Russo, C. Savaglio, 2016 IEEE First International Conference on Internet-of-Things Design and Implementation (IoTDI), Berlin, 259-264 (2016)

50. J. Pineiro-Chousa, M. Vizcaíno-González, M.Á. López-Cabarcos, N. Romero-Castro, Sustainability 9(3), 376 (2017)

51. K.T. Chui, W. Alhalabi, S.S.H. Pang, P.O de Pablos, R.W. Liu, M. Zhao, Sustainability 9, 2309 (2017)

52. N. Tuptuk, S. Hailes, J. Manuf. Syst. 47 93-106 (2018)

53. M. Gibbs, IZA World of Labor, 344 (2017) 
54. S. Singh, K. Sarkar, N. Bahl, International Journal of Research in Engineering, IT and Social Sciences 8(3), 6-12 (2018)

55. A. Bremer, Empirical Res. Voc. Ed. Train. 7, 8 (2015)

56. F.M. Zanzotto, arXiv:1710.08191 [cs.AI] (2017)

57. C.B. Frey, M.A. Osborne, The Future of Employment (2013)

58. A. 'Azzam, S. Indrawati, MATEC Web of Conferences 154, 01077 (2018)

59. J.J. Hughes, Surviving the Machine Age (2017)

60. J. Sujata, S. Saksham, G. Tanvi, Shreya, Procedia Computer Science 93, 902 - 909 (2016) 